\title{
Андреа Мейер-Фраати
}

\section{ВОЕННОЕ ТЕЛО В РОМАНЕ “АСАН» ВЛАДИМИРА МАКАНИНА}

Йенский университет имени Фридриха Шиллера, Германия, 07743 Йена, ул. Фюрстенграбен

Одной из особенностей романа «Асан» Владимира Маканина является то, что война описывается прежде всего со своей «телесной» стороны. Солдаты представлены как живые, раненые или мертвые тела, военная коммуникация осуществляется прежде всего телесными знаками; при разговорах персонажей обычно отмечается телесное качество голоса, нередко сравниваемого с голосами различных животных, что оказывается важнее, чем высказанные слова. Многочисленные телесные метафоры применяются и в связи с военными учреждениями и орудиями, так что создается впечатление одного большого военного тела. В статье эти телесные метафоры истолковываются с применением концептуальной теории метафоры Лакоффа и Джонсона с целью описания комплексной метафоры, лежащей в основе романного сюжета. Библиогр. 25 назв.

Ключевые слова: Маканин; роман «Асан»; война в литературе; тело; концептуальное смешение.

\section{THE BODY OF WAR IN VLADIMIR MAKANIN'S NOVEL ASAN}

\section{Andrea Meyer-Fraatz}

Friedrich-Schiller-Universität Jena, Institut für Slawistik, Fürstengraben 1, 07743 Jena, Germany

It is very conspicuous how in Vladimir Makanin's novel Asan war is depicted first of all from its corporal point of view. Soldiers are presented as living, wounded, or dead bodies. Communication in war is performed by means of corporal signs; when characters speak, it seems that the bodily quality of their voices is more important than the words they speak and the voices are often compared with voices of various animals. There are many corporal metaphors related to military institutions and weapons, so war turns out to be a tremendous military body. This paper interprets these bodily metaphors by means of Lakoff and Johnson's conceptual metaphor theory, thus describing a complex metaphor, underlying the novel's plot. Refs 25 .

Keywords: Makanin; the novel "Asan"; literature and war; the body; conceptual blending.

1. Роман «Асан», впервые опубликованный в 2008 г., - не первое произведение Маканина, которое можно рассматривать как часть Кавказского текста русской литературы ${ }^{1}$. Уже рассказ «Кавказский пленный» (1994) своим заглавием вписывается в пушкинскую и - еще в большей степени - толстовскую традицию ${ }^{2}$, причем

1 Понятие «Кавказский текст» используется аналогично понятию «Петербургский текст» [Топоров 1984]. Хотя имеется большое количество описаний различных региональных текстов русской литературы (ср., например, работы [Ф.Гимберт; А.Синицкой; O.Sazontchik]), и Кавказский текст довольно подробно и широко истолкован, но его основные оппозиции описывались редко. Ф. Гимберт при описании Кавказского текста ограничивается в основном оппозицией собственного и чужого. В неопубликованной вступительной лекции, прочитанной в Йене 5 января 2010 г., «Кавказский пленник - топографический топос русской литературы» мною (на основе пушкинского претекста, поэмы «Кавказский пленник») были выработаны следующие оппозиции: свое - чужое, (относительно) русское - кавказское, христианское - мусульманское, далекое - близкое, высокое - низкое (верх - низ), культура - природа. Эти оппозиции уже у Пушкина, однако, релятивируются и только в эпигональных текстах выступают в чистой форме; см.: [Layton, s. 156-174]. Hекоторые из этих оппозиций рассматриваются учеными не в семиотическом, а в культурологическом аспекте [S. Layton; V. Krüger].

2 Тема «Кавказского пленника» становилась предметом многочисленных литературоведческих и культурологических работ [Frank S.; Koznarsky T.; Armstrong T. P.; Grant B.; Migdissova S.].

(C) Санкт-Петербургский государственный университет, 2016 
замена архаизма «пленник» стилистически нейтральным выражением «пленный» подчеркивает современную позицию автора в почти двухсотлетнем Кавказском тексте. Заглавие романа «Андеграунд, или Герой нашего времени» (1998) также представляет собой ссылку на Кавказский текст; хотя Кавказ в этом романе не играет первостепенной роли, но выступает подспудно, на заднем плане (не только имплицитно, в заглавии, но и на уровне сюжета: речь идет, кроме прочего, об убийстве повествователем двух кавказцев).

Роман «Асан» в большей степени, чем роман «Андеграунд», развивает темы рассказа «Кавказский пленный», причем существенную роль, как и в рассказе, написанном более двадцати лет тому назад, здесь играет телесность, в особенности телесность солдата ${ }^{3}$. Тем не менее ни рассказ, ни роман не являются «военной прозой» в традиционном смысле, то есть они не описывают реалистически военные события и военный быт солдат. В таком подходе, как представляется, состоит существенная ошибка тех, кто критикует роман за то, что он не отвечает реалиям чеченской войны (например, [Бабченко]). Как будет показано далее, суть романа состоит не в реалистическом отображении мира, а, скорее, в том, что он отображает мифотворческую силу войны. Валерий Козлов вполне в положительном смысле подтверждает, что главный герой «Жилин [же] существо не менее сказочное, чем Грифон или Кетцалькоатль» [Козлов]. С. Чердиненко справедливо различает правду жизни и художественную правду [Чердиненко]. Юлия Щербинина в связи с романом Маканина пишет о «метафоре войны» [Щербинина]. Алла Латынина называет действие романа «притчей о военном камуфляже» и критически отмечает, что автор не делает различия между изображением «абстрактной» войны и реальной войны в Чечне [Латынина]. Во всяком случае, необходимо иметь в виду, что автор не описывает реальные события, а конструирует рассказ, в котором война (в очередной раз) оказывается бессмысленной.

События романа «Асан» рассказываются главным героем, майором Александром Сергеевичем Жилиным. Уже эти имя, отчество и фамилия указывают на Кавказский текст русской литературы, прежде всего на его основателя, Александра Сергеевича Пушкина, и на его продолжателя, Льва Николаевича Толстого: если Пушкин ранней южной поэмой «Кавказский пленник» как бы начинает писать Кавказский текст, то Толстой уже в третий раз (после эпигонского «Кавказского пленника» Лермонтова) использует это заглавие для одного из рассказов своей «Азбуки», главный персонаж которого носит фамилию Жилин. Но не только имя и фамилия протагониста и рассказчика отсылают читателя к Кавказскому тексту русской литературы; имена целого ряда персонажей совпадают с именами из произведений классической русской литературы. К таковым относятся, например, Руслан, один «добрый» чеченец, а также так называемый друг Жилина, Костыев, фамилия которого напоминает Костылина из толстовского «Кавказского пленника», а некоторые факты биографии (обрусевший чеченец из Петербурга, которому не раз удается спастись, возвращаясь в родной город) одновременно представляют собой ссылку на «Измаил-Бея» Лермонтова ${ }^{4}$. Но, как и в рассказе «Кавказский пленный», этими

3 В рассказе описываются связанные с телом проблемы походной солдатской жизни, ее сексуальные аспекты, ранения, смерть и, не в последнюю очередь, красота чеченского пленного.

4 Статья И.В. Кашиной по каким-то причинам не затрагивает интертекстуальный аспект ономастики у Маканина [Кашина]. 
ономастическими намеками Маканин скорее иронизирует над Кавказским текстом русской литературы, чем одобряет его. В рассказе красота ландшафта не в состоянии спасти мир, также как телесная красота пленного не спасает его от смерти. Уже в 1994 г. Маканин сомневается в этической силе литературной традиции. В романе «Асан» протагонист представляет собой на первый взгляд прагматического деятеля войны не без добрых намерений и ответственности, но в конце концов неконтролируемая динамика войны убивает и его. Эта неконтролируемость войны в метафорическом плане тесно связана с телесностью, играющей существенную роль и в тематическом плане.

2. Хотя современная война требует все меньше физической силы солдата и частично совсем может отказаться от непосредственного участия человека (например, когда используются так называемые дроны), для жизни солдата и для армии вообще все еще характерны физические аспекты. Тело солдата должно быть закаленным, и для достижения этой цели новобранцев тренируют. В бою тело солдата может быть ранено и искалечено; в худшем случае оно теряет жизнеспособность, становится мертвым 5 . Эти тривиальные констатации указывают на то, что в литературе о войне телесность всегда важна сама по себе. Однако, помимо этого, в романе Маканина телесность не только тематически входит в повествование, но и получает метафорический аспект, что в конце концов приводит к особой семантике военного тела.

В самом начале романа, в первой главе, описывается приезд «новоиспеченных солдат» [Маканин 2010, с.5]) как транспортировка анонимной массы пьяных тел или даже предметов, со всеми последствиями этого опьянения не только войной, но и Кавказом:

«Из Грозного колонной кое-как выползли, но дальше сделалось неладно. Пацанов внутри БТРов развезло, тошнило. Пацаны вылезли на броню, на воздух, но стали падать с боевых машин, как мешки... Едва на большой дороге прибавили в скорости... Как зрелые сливы, солдатики сыпались с БТРов прямо на дорогу.

А сзади шли грузовики. Смотреть в оба, мать вашу!... Один сломал руку... Другого солдата едва не придушило трансмиссией. А те, что внутри БТРов, спьяну блевали и задыхались... Воинская слава дается не сразу.

Колонна притормозила, и солдатня инстинктом, без приказа сама перебирается с боевых машин в два порожних грузовика... Перелазят... Кой-кому приходится помочь. Совсем отключившихся Жора и сержант Борзой перебрасывают враскач - раздва! - через борт. Всех туда... И никакой почменной переклички!» [Маканин 2010, c. 105].

Единственные упомянутые имена относятся к ответственным за транспортировку. Интересно, что солдаты, с одной стороны, сравниваются с неодушевленными предметами (мешками), а с другой - с органической материей («как зрелые сливы»). Таким образом, эта цитата в известном смысле содержит квинтэссенцию романа как целого, что я надеюсь показать в дальнейшем.

Главный персонаж, майор Александр Сергеевич Жилин, рассказывает этот эпизод не без иронии. У него довольно трезвое отношение к военным событиям

5 Различным аспектам изменения тела в связи с войной посвящен, например, сборник «War and the Body. Militarisation, practice and experience» (McSoreley 2013). 
и окружающим людям; они становятся для него безымянными, как, например, в другом эпизоде, когда в его джипе везут убитого в засаде солдата: «Оказался опрятен в смерти. Две пули прямо под сердие, крови мало» [Там же, с. 38]. Однако необходимо добавить, что в дальнейшем рассказчик все-таки спрашивает себя, какой смысл имела эта короткая жизнь. Главным, вопреки амбивалентным ощущениям по отношению к разным людям, является то, что майор Жилин оказывается профессионалом войны, в особенности как торговец бензином, таким образом выкупающий дорогу для своих перевозящих бензин колонн. Им создана целая сеть из военных и чеченцев, которая позволяет ему не только перевозить бензин для военных целей с одного места на другое, но и обогатиться лично, чтобы построить в далекой России, над некой рекой, себе и своей семье домик. Эту сеть, которая обеспечивает снабжение танков, вертолетов и военных грузовиков бензином, метафорически можно понять как сеть жил в военном организме: «Бензин - кровь войны... На складе я распределяю бензин по заказам воинских частей. Но плюс -я еще и обеспечиваю доставку. Это моя личная инициатива... Война стала исключительно горной, и потому в нынешней войне доставка - это все. И потому каждая десятая бочка - мой навар» [Там же, с. 39].

С этой точки зрения фамилия рассказчика приобретает качество говорящего антропонима. Жилин оказывается чем-то большим, чем «жилы» бензина. Особенно в опасных или напряженных ситуациях [Там же, с. 17, 156, 180, 190, 215, 247, 430] и даже в телефонных разговорах с женой [Там же, с. 45, 322] он не раз упоминает свое сердце, и вполне оправданно говорить о протагонисте как о «моторе» военного бензинового бизнеса. Метафора бензина как крови войны указывает на амбивалентность войны, как она описывается в романе. С одной стороны, война представлена как огромный организм, с другой стороны, этот организм на самом деле не живое существо, а, скорее, машина - или даже и то и другое. Эта двойственность машины и организма повторяется при описании, например, движения колонн, когда упоминаются парализованность колонны после нападения ( Подбили замыкавший колонну танк. Колонна невелика и оказалась сразу парализована...» [Там же, c.75]), ползание тяжелых танков («И за БМДэшкой, за Хворем полз тяжельй танк» [Там же, с.172]), животные или человеческие звуки, производимые танками («Еще и крикну им вслед - вслед весело пердящему БТРу» [Там же, с.212]). Одна из потерянных колонн описывается словами: «От такой колонны веяло теплом. У нее была настоящая душа! <..> Живое существо всегда жаль» [Там же, с. 282]. Когда майор Гусарцев, близкий помощник Жилина, топит в болоте грузовик, из которого он продал оружие и который нагрузил металлическим мусором, упоминается, что «последний пузырь воздуха был, как шумный прощяальньй вдох-выцох» [Там же, c. 93]. А джип, в котором сам Жилин в конце романа умирает и который сбивается с пути и повреждается, описывается словами: «А не примеченный им джип так и остался носом в канаве. Застыл там... Возможно, с обидой... <..> А теперь лежи, броченный на обочине. Со свернутым рылом!» [Там же, с. 478].

Одушевлению или даже антропоморфизации подвергается не только военный транспорт, но и то, что обеспечивает «нормальный» ход войны, - деньги, которые метафорически связаны с организмами: «У моего камуфляжа за долгое время сильно оттянулся левый карман. Разного рода тяжестью... Сейчас тяжести ни малейшей, пуст. Так что глядел мой карман, как пасть, голодная и жаждущзая. Руслан 
бросил туда, в пасть, пачку денег. Легким движением кисти... Никакой тайны. Это просто доля. За привезенный мазут наш приработок... Потому что хоть что-то мы в в/ч за №... привезли... Надо сказать, что в пасть моего кармана вошла бь бо́льшая пачка. Гораздо бо́льшая... Карман бъ проглотил, не попернувшись» [Там же, с. 475].

Такое всеобщее одушевление и антропоморфологизация войны, выражающиеся в многочисленных телесных метафорах, сопровождаются характерной телесной коммуникацией. Когда люди говорят, почти всегда упоминается качество голоса, то есть подчеркивается телесность речи, нередко и в терминах «звериных» звуков. Один характерный пример связывает упомянутую выше специфическую телесную метафорику с указанием телесного качества голоса: "Полевой говорил, гортанно вскрикивая... На высокой ноте... Доллары уже жгли ему нутро. Сильнейшая наших дней изжога» [Там же, с.22]. Часто жесты, мимика, движения тела заменяют слова, или особенно подчеркиваются телесные выражения, сопровождающие слова; иногда рассказчик даже пытается «читать» жесты и мимику солдат, переводить их в вербальные выражения. О контуженном солдате Алике, например, он рассказывает, как тот, когда он хочет позвонить матери, не может вспомнить телефон:

«Трубку взял Алик, но вот его-то память как раз подвела. Он, вроде бь, знал номер. Он тыкал пальцем в иифры... Он, сколько мог, тыкал... Сердился. Вдруг шипел на случайный чей-то голос: „Да заткнись же!.. Брось трубку, кретин!.. Не тебе звоню!“ Алик снова и снова пробегал пальцем по иифрам. Уже ощупью ища полузабытый номер... „Мама?! - спрашивал. - Мама?!“

Он вдруг замер. Смотрел на трубку. Весь сокрушенный... Он словно знал, что чудо не для нас. Вот оно, в его руках, чужое чудо... Я вдруг подумал, что он имякнет мою трубку о пол. Мне не понравились его глаза. Они наливались бельм иветом.

Я протянул руку, а он не отдавал.

- Рядовой Евский!

Я грозно рявкнул. И сам, шагнув ближе, забрал трубку из его зачепеневщей руки» [Там же, с. 189-190].

Эта цитата охватывает множество аспектов телесной коммуникации, характерной для войны, как она описывается в романе, — от «звериного» качества голоса до замены слов движениями. На фоне выразительно подчеркнутой телесности коммуникации на войне сама война представляется как специфическая форма коммуникации. При этом каждая сторона «говорит» своим специфическим (телесным) языком, а полулегальная торговля бензином главного персонажа как бы является общим языком обеих сторон.

3. Метафора «бензин - кровь войны» оказывается существенной для тематики данного романа. Бензин и кровь представляют собой предметы, принадлежащие физическому миру. Однако в романе важна и метафизическая сторона, которая, может быть, оказывается даже важнее, чем физическая, если принять всерьез заглавие романа «Асан». Об Асане рассказывает «читающий» генерал Базанов, начальник майора Гусарцева, прославившийся в Афганистане, а на чеченской войне не выполняющий на самом деле никакой важной функции, что позволяет ему заниматься историей чеченцев. Не раз он рассказывает о древнем боге Асане, в которого чеченцы верили до принятия сначала христианства, а потом мусульманства. В отличие от мусульманского бога, Асан допускает кровную месть, и это именно 
он требует крови во время войны. Этот бог, как утверждает, например, Алла Латынина, является выдумкой Маканина ${ }^{6}$. Его персонаж, генерал Базанов, выводит имя этого бога от имени Александра Великого, завоевавшего Кавказ в IV в. до н. э. По внутренней логике романа Асан в настоящее время требует уже не только человеческой крови, но и крови войны, бензина. Непосредственно перед смертью сам рассказчик (по имени Александр), когда он в последний раз может решить проблему свободной дороги доставкой бензина, чувствует себя богом Асаном. Он слышит, как окружающие его чеченцы обращаются к нему «Асан» (другие чеченцы на протяжении романа называют его Сашиком). Этот последний эпизод, в котором майор Жилин как будто превращается в старинного бога Асана, можно понять как иронический комментарий к судьбе этого персонажа и его деятельности, описанной в романе. Жилин представлен в основном как добрый, совестливый и ответственный человек, не только обогащающий себя лично торговлей бензином, но и играющий роль посредника между враждебными сторонами. Тот факт, что рассказчика случайно убивает уже упомянутый контуженый солдат Алик, причем именно в тот момент, когда он делает ему и другому контуженому солдату одолжение, дополнительно подчеркивает ту бессмысленность войны, которую сам Жилин констатировал раньше: «Война сама по себе абсурдна... Пока она не кончилась <... война абсурдна, пока нет победителей» [Там же, с. 255]. Жилин своей торговлей сохраняет «бессмысленной войне» жизнь, но, как и другие члены сети, обеспечивающей эту деятельность, он в конце концов умирает. Огромное тело войны съедает само себя.

Метафоризация войны как огромного тела оказывается существенной для романа Маканина. Она настолько вездесуща, что частотность ее использования позволяет обратиться к концептуальной теории метафоры Лакоффа и Джонсона (conceptual metaphor theory) и понятию концептуальных интеграционных сетей Фоконье и Турнера (conceptual integration networks), хотя как социолингвистические теории они обычно используются при анализе разговорной речи, а не литературных текстов. Применив эти теории к роману Маканина, можно сказать, что в нем война приравнивается к телу, а Жилин становится сердцем этого тела. Но, в отличие от изучения стереотипов (обычной области применения этих теорий), по отношению к литературным произведениям эти методы часто используются именно с целью демонтажа стереотипов (ср.: [Wojcik, S. 66-83]). В данном случае роман сначала конструирует упомянутые равенства, которые можно оценить весьма амбивалентно. С одной стороны, Жилин как продавец бензина чеченцам становится посредником между двумя враждующими сторонами. С другой стороны, он использует состояние войны, чтобы обеспечить собственное благосостояние, переводя жене нелегально заработанные таким образом деньги. Играя роль продавца бензина, он как будто обеспечивает бесконечность войны. Но в ходе романа постепенно, один за другим, умирают товарищи Жилина. Сам он в последнем эпизоде, непосредственно перед смертью, чувствует себя богом Асаном. В этой роли он как будто выпадает из метафоры и играет другую роль, которая в конечном счете оказывается неуместной. Его смерть в некотором смысле случайна; однако это лишь подчеркивает глубинное противоречие с внутренним миром Жилина, его

${ }^{6}$ Некоторые критики даже упрекают Маканина за то, что он выдумывает мифологическую фигуру (например, А. Бабченко). 
сознанием, что он - как торговец бензином - неуязвим, а потому не может быть убит собственными людьми. В этом заключается не только трагизм судьбы главного персонажа, но и скрытая критика бессмысленности (чеченской) войны вообще. Таким образом становится ясно, что даже самые опытные военные не могут спастись от смерти раз и навсегда и даже тело военного человека обречено на гибель. Но, в отличие от обыкновенного живого организма, тело войны не может умереть, потому что его сердце становится бессмертным (богом). В этом и состоит ирония конструкции комплексной метафоры военного тела в романе Маканина.

\section{Литература}

Бабченко А.А. Фэнтэзи о войне на тему «Чечня». 2008. URL: http://artofwar.ru/b/bachenko_a_a/ text_0240.shtml (дата обращения: 09.06.2015).

Гимберт Ф. Кавказский текст русской литературы // Континент. 2000. № 104. URL: http://magazines. russ.ru/continent/2000/104/gr82pr.html (дата обращения: 17.03.2014).

Кашина И. В. Антропонимы в романе В. Маканина «Асан» // Вестник ТГгпУ. 2009. № 1 (16). URL: http://cyberleninka.ru/article/n/antroponimy-v-romane-v-makanina-asan (дата обращения: 09.06.2014).

Козлов В. Экзистенциальный задачник. Владимир Маканин // Вопросы литературы. 2010. № 1. URL: http://magazines.russ.ru/voplit/2010/1/ko5.html (дата обращения: 12.08.2014).

Латьнина А. Притча о военном камуфляже // Новый мир. 2008. № 12. URL: http://magazines.russ.ru/ novyi_mi/2008/12/la13pr.html (дата обращения: 12.08.2012).

Маканин В. Андеграунд, или Герой нашего времени. М.: Эксмо, 2008. 736 с.

Маканин В. Асан. М.: Эксмо pocketbook, 2010. 480 c.

Маканин В. Кавказский пленный // Новый мир. 1995. № 4. URL: http://magazines.russ.ru/novyi_ $\mathrm{mi} / 1995 / 4 /$ makanin.html (дата обращения: 12.08.1012).

Синицкая А. К проблеме пространственности в литературе // Вестник Самарского гос. ун-та. 2004. № 1. URL: http://vestnik.ssu.samara.ru/gum/2004web1/litr/200410601.html (дата обращения: 03.01.2010).

Чердиненко С. Уравнение Маканина // Вопросы литературы. 2009. № 5. URL: http://magazines.russ.ru/ voplit/2009/5/ch12pr.html (дата обращения: 02.08.2014).

Щербинина Ю. Метафора войны: художественные прозрения или тупики? // Знамя. 2009. № 5. URL: http://magazines.russ.ru/znamia/2009/5/shl15pr.html (дата обращения: 12.08.2014).

Armstrong T.P. The Image of the Prisoner of the Caucasus in Nineteenth and Twentieth Century Russian Literature and Culture from Pushkin to Makanin // The Russian Review (PolskieTowarzystvo Rusycystyczne). 2004. N 26/3. P. 33-50.

Fauconnier G., Turner M. The Way We Think. Conceptual Blending and the Minds Hidden Complexities. New York: Basic Books, 2002. 440 p.

Frank S. Gefangen in der russischen Kultur: Zur Spezifik der Aneignung des Kaukasus in der russischen Literatur // Die Welt der Slaven. 1998. Bd. 43. S.61-84.

Grant B. The Good Russian Prisoner: Naturalizing Violence in the Caucasus Mountains // Cultural Anthropology. 2005. N 20/1. S.39-67.

Grant B. The Captive and the Gift: Cultural Histories of Sovereignty in Russia and the Caucasus. Ithaca, 2009. $188 \mathrm{p}$.

Iordanova D. Prisoner of the Mountains. (Kavkazskii plennik) by S. Bodrov, B. Giller, A. Aliev // The Russian Review. 1997. Vol.56, N 3. P. 451.

Koznarsky T. A Prisoner of the Caucasus and a Captive of Vernacular // Toronto Slavic Quarterly. 2003. N 6. URL: http://sites.utoronto.ca/tsq/06/index06.shtml (дата обращения: 17.10.2015).

Krüger V. Identität - Alterität - Hybridität. Zur Funktion des Kaukasus in der russischen romantischen Literatur und im Film des postsowjetischen Russlands. PhD dissertation (Philology) Freiburg i. Br., 2008. URN: urn:nbn:de:bsz:25-opus-71678. URL: https://www.freidok.uni-freiburg.de/fedora/objects/freidok:7167/datastreams/FILE1/content (дата обращения: 07.07.2016).

Lakoff M., Johnson M. Metaphors we live by. Chicago; London: University of Chicago Press, 1980. 242 p. 
Layton S. Russian Literature and Empire. Conquest of the Caucasus from Pushkin to Tolstoy. Cambridge: Cambridge University Press, 1994. 354 p.

McSorley K. (ed.) War and the Body. Militarisation, Practice and Experience. London; New York: Routledge, 2013. $252 \mathrm{p}$.

Migdissova S. An Analysis of a Russian Cultural Phenomenon: A. S. Pushkin's 'Prisoner of the Caucasus' and Beyond // Dissertation Abstracts International. 2012. LXXIII 2, McGill U, 2011 Abstract No: NR77527.

Sazontchik O. Zur Problematik des Moskauer Textes der russischen Literatur. Versuch einer Bestimmung anhand von Werken Boris Pasternaks, Michail Bulgakovs, Venedikt Erofeevs, Jurij Trifonovs und Vasilij Aksenovs. Frankfurt/M.: Peter Lang, 2007 (= Slavische Literaturen. Texte und Abhandlungen. Bd. 39). 428 p.

Wojcik P. Das Stereotyp als Metapher. Zur Demontage des Antisemitismus in der Gegenwartsliteratur. Bielefeld: transcript Verlag, 2013. 306 S.

Для цитирования: Мейер-Фраатц А. Военное тело в романе «Асан» Владимира Маканина // Вестник СПбГУ. Серия 9. Филология. Востоковедение. Журналистика. 2016. Вып. 3. С.120-128. DOI: $10.21638 / 11701 /$ spbu09.2016.314.

\section{References}

Armstrong T.P. The Image of the Prisoner of the Caucasus in Nineteenth and Twentieth Century Russian Literature and Culture from Pushkin to Makanin. The Russian Review (PolskieTowarzystvo Rusycystyczne), 2004, vol.26/3, pp.33-50.

Babchenko A. A. Fentezi o voine na temu "Chechnia" [Fantasy about War in Chechnya]. 2008. Available at: http://artofwar.ru/b/bachenko_a_a/text_0240.shtml (accessed: 09.06.2015). (In Russian)

Cinitskaia A. K probleme prostranstvennosti v literature [Towards Spaceness in Literature]. Vestnik Samara State University. Ser. Literary Studies, 2004, vol.1. Available at: http://vestnik.ssu.samara.ru/ gum/2004web1/litr/200410601.html (accessed: 03.01.2010). (In Russian)

Cherdinenko S. Uravnenie Makanina [Makanin Equitation]. Voprosy literatury, 2009, vol.5. Available at: http://magzines,ru/voplit/2009/5/ch12pr.html (accessed: 02.08.2014). (In Russian)

Fauconnier G., Turner M. The Way We Think. Conceptual Blending and the Minds Hidden Complexities. New York, Basic Books Publ., 2002. 440 p.

Frank S. Gefangen in der russischen Kultur: Zur Spezifik der Aneignung des Kaukasus in der russischen Literatur [Trapped in Russian Culture: Appropriation of the Caucasus in Russian Literature]. Die Welt der Slaven, 1998, Bd. 43, pp. 61-84.

Gimbert F. Kavkazskii tekst russkoi literatury [Caucasian Text of the Russian Literature]. Kontinent, 2000, vol. 104. Available at: http://magazines.russ.ru/continent/2000/104/gr82pr.html (accessed: 17.03.2014). (In Russian)

Grant B. The Good Russian Prisoner: Naturalizing Violence in the Caucasus Mountains. Cultural Anthropology, 2005, vol.20/1, pp.39-67.

Grant B. The Captive and the Gift: Cultural Histories of Sovereignty in Russia and the Caucasus. Ithaca, 2009. $188 \mathrm{p}$.

Iordanova D. Prisoner of the Mountains. (Kavkazskii plennik) by S. Bodrov, B. Giller, A. Aliev. The Russian Review, 1997, vol. 56, no. 3, p. 451.

Kashina I. V. Antroponimy v romane V. Makanina "Asan" [Personal names in the novel Asan by V. Makanin]. Filologiia i kul'tura (Vestnik TGGPU) [Philology and culture], 2009, vol.1 (16). Available at: http:// cyberleninka.ru/article/n/antroponimy-v-romane-v-makanina-asan (accessed: 09.06.2014). (In Russian)

Kozlov V. Ekzistentsial'nyi zadachnik. Vladimir Makanin [Existential Task Book. Vladimir Makanin]. Voprosy literatury, 2010, vol.1. Available at: http://magazines.russ.ru/voplit/2010/1/ko5.html (accessed: 12.08.2014). (In Russian)

Koznarsky T. A Prisoner of the Caucasus and a Captive of Vernacular. Toronto Slavic Quarterly, 2003, vol.6. Available at: http://sites.utoronto.ca/tsq/06/index06.shtml (accessed: 17.10.2015).

Krüger V. Identität - Alterität - Hybridität. Zur Funktion des Kaukasus in der russischen romantischen Literatur und im Film des postsowjetischen Russlands. PhD dissertation (Philology) Freiburg i. Br., 2008. URN: urn:nbn:de:bsz:25-opus-71678. Available at: https://www.freidok.uni-freiburg.de/fedora/ objects/freidok:7167/datastreams/FILE1/content (accessed: 07.07.2016). 
Lakoff M., Johnson M. Metaphors we live by. Chicago, London, University of Chicago Press, 1980. 242 p.

Latynina A. Pritcha o voennom kamufliazhe [Story about War Camouflage]. Novyi mir, 2008, vol. 12. Available at: http://magazines.russ.ru/novyi_mi/2008/12/la13pr.html (accessed: 12.08.2012). (In Russian)

Layton S. Russian Literature and Empire. Conquest of the Caucasus from Pushkin to Tolstoy. Cambridge, Cambridge University Press, 1994. 354 p.

Makanin V. Andegraund, ili Geroi nashego vremeni [Underground, or the Hero of Our Time]. Moscow, Eksmo Publ., 2008. 736 p. (In Russian)

Makanin V. Asan [Asan]. Moscow, Eksmo pocketbook Publ., 2010. 480 p. (In Russian)

Makanin V. Kavkazskii plennyi [Caucasian Captive]. Novyi mir, 1995, vol. 4. Available at: http://magazines. russ.ru/novyi_mi/1995/4/makanin.html (accessed: 12.08.1012). (In Russian)

McSorley K. (ed.) War and the Body. Militarisation, Practice and Experience. London, New York, Routledge, 2013. $252 \mathrm{p}$.

Migdissova S. An Analysis of a Russian Cultural Phenomenon: A. S. Pushkin's 'Prisoner of the Caucasus' and Beyond. Dissertation Abstracts International. 2012. LXXIII 2, McGill U, 2011 Abstract No: NR77527.

Sazontchik O. Zur Problematik des Moskauer Textes der russischen Literatur. Versuch einer Bestimmung anhand von Werken Boris Pasternaks, Michail Bulgakovs, Venedikt Erofeevs, Jurij Trifonovs und Vasilij Aksenovs. Frankfurt/M., Peter Lang, 2007 (= Slavische Literaturen. Texte und Abhandlungen [Slavic Literatures. Texts and Treatises]. Bd. 39). 428 p.

Shcherbinina Iu. Metafora voiny: khudozhestvennye prozreniia ili tupiki? [Metaphor of War: Literal Clarification or Blind Alley?] Znamia, 2009, vol.5. Available at: http://magazines.russ.ru/znamia/2009/5/ shl15pr.html (accessed: 12.08.2014). (In Russian)

Wojcik P. Das Stereotyp als Metapher. Zur Demontage des Antisemitismus in der Gegenwartsliteratur. Bielefeld, transcript Verlag, 2013. 306 S.

For citation: Meyer-Fraatz A. The body of war in Vladimir Makanin's novel Asan. Vestnik SPbSU. Series 9. Philology. Asian Studies. Journalism, 2016, issue 3, pp. 120-128. DOI: 10.21638/11701/spbu09.2016.314.

Статья поступила в редакцию 21 октября 2015 г.

Статья рекомендована в печать 28 марта 2016 г.

Контактная информация:

Мейер-Фраати Андреа - доктор наук, профессор; Andrea.Meyer-Fraatz@uni-jena.de

Meyer-Fraatz Andrea - Prof. Dr.; Andrea.Meyer-Fraatz@uni-jena.de 